\title{
Juventud y política en la apertura democrática. Una mirada sobre el Movimiento de Juventudes Políticas marplatense (1983-1987)
}

\author{
Maria Constanza Castro \\ Universidad Nacional de Mar del Plata, Argentina \\ constanzacastro2593@gmail.com
}

\section{ReSUMEN:}

Este trabajo busca ampliar el conocimiento sobre las juventudes políticas durante la última apertura democrática. Para ello, se propone estudiar el Movimiento de Juventudes Políticas, una experiencia transversal que reunió a las juventudes de los principales partidos políticos del país entre 1983 y 1987. Con este objetivo, se intenta reconstruir las condiciones de emergencia del movimiento, identificar los espacios en los cuales se canalizó el activismo político juvenil para reconocer y comprender las ideas y las prácticas que nutrieron su cultura política.

Palabras CLAVE: Juventudes políticas, Militancia, Recuperación democrática.

\section{ABSTRACT:}

This paper seeks to broaden knowledge about the political role of youth since the comeback of democracy in Argentina (after the dictatorship period). In order to do so, the paper proposes to study the role of youth in politics, a transversal experience that brought together the youth of the country's main political parties between 1983 and 1987. As a result, there is an attempt to reconstruct the emergency conditions of these historical facts. And also there is an attempt to identify how youth political activism was born, so as to be able to recognize, and understand which were the ideas and lines that turned the involvement of the youth in politics into one of the most salient features of today's Argentinian political culture.

KEYWORDS: Political youth, Militancy, Democratic recovery.

\section{INTRODUCCIÓN}

Este artículo analiza la experiencia del Movimiento de Juventudes Políticas (MOJUPO) durante la última apertura democrática a escala local en la ciudad de Mar del Plata. El MOJUPO se trató de una iniciativa que aglutinó a los dirigentes juveniles de distintos partidos políticos, y si bien tuvo su epicentro en la Capital Federal, su estructura organizativa se replicó en distintas localidades del país que, en algunos casos, le imprimieron características distintivas.

El golpe de Estado del 24 de marzo de 1976 significó un duro revés para la juventud dado que el régimen militar clausuró la actividad política e implementó acciones represivas y disciplinadoras -particularmente sobre ese segmento de la población- que limitaron su actuación. No obstante, a fines del año 1981, con la asunción de la nueva Junta Militar a cuyo mando estuvo Roberto Viola, se evidenció una relativa distensión de la actividad política y una etapa de mayor cuestionamiento hacia el régimen. Esas críticas eclosionaron y crecieron exponencialmente luego de la derrota bélica en Malvinas. Con una dictadura en retirada y una sociedad postergada en sus derechos, un sector importante de la juventud se involucró en la recomposición de sus ámbitos de participación, especialmente en la universidad y en los partidos políticos.

En ese marco, fue posible la emergencia de una experiencia política juvenil transversal a los partidos que expresara las principales preocupaciones y demandas de los jóvenes en el complejo proceso de reconstrucción del sistema democrático y sus instituciones. Partiendo de esa coyuntura, el objetivo del artículo consiste en reconocer las transformaciones que operaron en la concepción sobre la militancia política en la sociedad y cómo se percibieron los jóvenes durante la etapa final del autodenominado "Proceso de Reorganización Nacional” y el primer periodo del gobierno democrático de Raúl Alfonsín. Al mismo tiempo, nos interesa 
dar cuenta de los espacios a través de los cuales se canalizó el activismo político juvenil con el propósito de reconocer y comprender las ideas y las prácticas que nutrieron su cultura política. ${ }^{1}$

Para alcanzar este objetivo, el trabajo se organiza en dos apartados. El primero de ellos hace foco en las representaciones que la sociedad elaboró en torno a "la militancia" y las transformaciones asociadas a ella a lo largo del periodo. Por su parte, el segundo apartado explora la participación juvenil en el MOJUPO cuyo foco está dirigido a observar las coincidencias generales entre las distintas expresiones juveniles de los partidos políticos, en el escenario capitalino y su correlato en la ciudad balnearia.

La hipótesis que sostiene este trabajo es que las juventudes políticas durante la apertura democrática se autorrepresentaron como disruptivas respecto de la generación anterior, caracterizada bajo el estigma de la violencia política. En una coyuntura de valorización de la democracia y sus instituciones, la ruptura estuvo dada por el rol de los jóvenes que consistió en militar por y para la democracia. No obstante los esfuerzos diferenciadores, el repertorio discursivo, sus referentes simbólicos y sus demandas políticas fueron expresados en los mismos términos de la etapa que se esforzaban por dejar atrás.

\section{IMAGINARIOS Y REPRESENTACIONES SOBRE LA PARTICIPACIÓN POLÍTICA JUVENIL EN LA APERTURA DEMOCRÁTICA}

El activismo juvenil adquirió un fuerte protagonismo durante el estallido de la Guerra de Malvinas y se aceleró aún más luego de la derrota bélica, primero a través de la organización de campañas de donaciones para los combatientes, luego en torno a una posición de rechazo hacia la cúpula militar. ${ }^{2}$ Como bien ha señalado Lorenz (2006), la juventud protagonizó simbólica y materialmente la guerra. En razón de su edad fueron bautizados como "los chicos de la guerra", y en ellos se concentraron las explicaciones sobre el conflicto y la derrota. En el sentido común dominante de la sociedad, la guerra estaba incorporada al vocabulario cotidiano en asociación al universo de la violencia política y la muerte. Esa visión anclaba su origen en la "subversión" y el "terrorismo". Con Malvinas, en oposición a la juventud "terrorista", se construyó otra juventud dotada de virtudes patrióticas, con ideales de nación y futuro (Lorenz, 2006). De esta forma, en el contexto de la salida del gobierno de facto se produjo la identificación simbólica de los caídos en la guerra y los sobrevivientes con las víctimas de la dictadura militar, acrecentándose los cuestionamientos a la corporación castrense. Así, Malvinas se transformó en la causa de una "generación" de jóvenes que se identificó con ella otorgándole también un peso simbólico preponderante a lo largo de toda la década. ${ }^{3}$

No obstante ello, uno de los principales desafíos que enfrentó la naciente democracia en 1983 fue la reinstitucionalización política y social, entendiéndose por ella la recomposición de los vínculos establecidos entre el espacio público, la ciudadanía y el espacio político que resultaron en una creciente demanda de participación (Quiroga, 1996). Es así que, en este periodo, se construyó un consenso en el cual el actor principal fue el ciudadano cuyo acto político por excelencia era la participación en elecciones a través del voto y en donde la representación se canalizó - nuevamente- a través de los partidos políticos (Vommaro y Blanco, 2017 , p. 8). Como actores imprescindibles en la vida interna de todo partido y al perder cierta vigencia las representaciones que los asociaban a la peligrosidad y le atribuían valoraciones negativas -heredadas de la etapa revolucionaria que los identificaban con la violencia política-, los sectores juveniles cumplieron un rol de primer orden en la apertura democrática. Fue así que su participación en la escena política fue acompañada de una revalorización de lo juvenil que aparecía representado como motor de cambios y transformaciones en la sociedad. No obstante, la concepción sobre la militancia política en el imaginario social fue paulatinamente modificándose de modo progresivo. Julieta Quirós (2014) señala que, al término de la última dictadura militar, la representación sobre la militancia había quedado fuertemente impregnada por el activismo de las organizaciones armadas. La (re)politización que caracterizó la recuperación democrática no alteró la significación de "lo militante" que continuó asociada al estigma de la izquierda revolucionaria. Solo adquirió 
nuevos sentidos y usos sociales de la mano del activismo por los derechos humanos que permitió construir un nuevo sentido de "militar en y por la democracia" (p. 251). En buena medida, ese cuadro de situación obedeció a que -al menos hasta la publicación del informe del Nunca Más-, a fines del año 1984, se trató de un periodo específico en el que los discursos y las representaciones vinculadas al pasado autoritario tuvieron una fuerte continuidad. En efecto, las percepciones sociales fueron mucho más complejas y variadas dado que no existió un cambio inmediato sino más bien convivieron una multiplicidad de sentidos, algunos de los cuales cristalizaron tiempo más tarde (Feld y Franco, 2015, p. 360).

Entrados los años ochenta, la reivindicación de la democracia como sistema político de gobierno y la defensa de los derechos humanos como causa principal dotaron de nuevos significados a la concepción del militante. Estos lemas fueron capitalizados por el radicalismo que se presentó como la fuerza política capaz de incorporar a un vasto sector juvenil sin experiencia política previa (Quirós, 2014, p. 251). En este sentido, es posible afirmar que el discurso alfonsinista interpeló exitosamente a este sector al delimitar una frontera política que estableció una diferenciación respecto al pasado violento y autoritario de los últimos años (Aboy Carlés, 2001). A modo ilustrativo, estos rasgos pueden identificarse en las repetidas contratapas que aparecían en la revista Generación '83-periódico oficial de un sector de la Juventud Radical- en la cual se afirmaba que "los niños nacerán con un arma bajo el brazo. Las nuevas generaciones nacerán en democracia, el arma más poderosa para defender sus verdades" (Generación '83, N. $\left.{ }^{\circ} 3,1984\right){ }^{4}$

Como ha señalado Vicente Palermo (1987), la construcción de la propuesta política de Raúl Alfonsín se basó en garantizar valores democráticos de respeto por la libertad, la valoración de los derechos individuales y el fin de toda práctica autoritaria que resultaron en la reinvención de las juventudes ya no como sujetos de la revolución sino de la democracia (p. 158). En este esquema, el peronismo apareció como la antítesis de la propuesta alfonsinista y su referencia se hallaba en la cultura política revolucionaria de los años setenta carente de un aggiornamiento adaptado a los nuevos tiempos. No obstante, cabe destacar que, si bien el alfonsinismo fue el que concitó una mayor participación juvenil, también existieron otros espacios en el marco de los partidos políticos que lo cuestionaron y se posicionaron como alternativa; tales fueron los casos de la Juventud Intransigente (JI), la Federación Juvenil Comunista (FJC) o las Juventudes Socialistas, entre las más relevantes.

\section{El MOJUPO MARPLATENSE}

Hacía el final del régimen dictatorial y ante el escenario de presión ejercido por el creciente activismo, los jóvenes alcanzaron un mayor protagonismo. La conformación de la Multipartidaria, en julio de 1981, tuvo su correlato en el plano juvenil en la conformación del MOJUPO que desarrollaron tiempo más tarde, en 1983, las ramas juveniles de los principales partidos políticos estimulados por el contexto de una progresiva apertura de la actividad política. ${ }^{5}$ Como antecedente de una experiencia similar de solidaridad entre agrupaciones juveniles en pos de un objetivo compartido, cabe destacar la conformación de la Coordinadora de Juventudes Políticas, devenida luego en Juventudes Políticas Argentinas, durante los años 1973 y 1974 y cuyo impulso inicial fue el rechazo al golpe de Estado a Salvador Allende en Chile (Larrondo y Cozachcow, 2017, p. 54). ${ }^{6}$

A nivel nacional, los orígenes del MOJUPO se remontan hacia fines del año 1982. No obstante, su conformación formal se produjo en la Capital Federal durante el mes de mayo de 1983 a partir del nucleamiento de las juventudes de once partidos políticos. ${ }^{7}$ La irrupción en la escena pública se produjo con la realización de la "Marcha por la Paz y la Democracia" que fue convocada bajo el lema "contra la desestabilización y la guerra, por una transición hacia la democracia libre, sin condicionamientos ni proscripciones" (Clarín, 30/6/1983, p. 9) Sus integrantes destacaban como objetivo común del conjunto de las juventudes políticas "la unidad nacional y popular, para garantizar la conquista efectiva de la democracia en 
el país" (Clarín, 1/7/1983, p.18). Si bien esta experiencia tuvo un cariz netamente centralista, esta estructura se replicó rápidamente en distintas ciudades del país que imprimieron sus propias características a ese espacio.

Larrondo y Cozachcow (2017) han diferenciado dos momentos específicos del MOJUPO: el primero, se extiende hasta el año 1985 y está signado por la constante convocatoria a movilizaciones; y el segundo, ubicado entre los años 1985 y 1987 aproximadamente, caracterizado por los acuerdos de cúpulas entre los dirigentes juveniles y una progresiva disgregación producto de las tensiones generadas con la Juventud Radical en una coyuntura de retroceso en las políticas económicas y en materia de derechos humanos durante el gobierno radical.

Como señalan los autores, luego de la exitosa convocatoria a la marcha inicial, el impulso del agrupamiento juvenil fue en ascenso. Su visibilidad fue tal que fueron recibidos por el presidente electo Alfonsín, a quien entregaron un documento en el que manifestaban la aspiración "de una nueva Argentina, nacional, popular, democrática y transformadora, [que] deberá surgir de los escombros, sancionando a todos los responsables de la destrucción nacional y la descomposición social". Al mismo tiempo, rescataban el accionar político promovido por el MOJUPO basado en la "convivencia democrática, el respeto mutuo y el pluralismo ideológico" (Clarín, 4/12/1983, p. 4). Durante el transcurso del año 1984 las coincidencias también se expresaron en torno a la cuestión de los derechos humanos al solicitar el procesamiento de Benjamín Menéndez y convocar de manera conjunta a la movilización con motivo de la entrega del informe de la Comisión Nacional por la Desaparición de Personas (CONADEP) (Clarín, 25/8/1984, p. 8 y 18/9/1984, p.12). ${ }^{8}$ A fines de ese mismo año, para reforzar sus objetivos iníciales, por iniciativa de la juventud de la Democracia Cristiana, el MOJUPO lanzó el documento "Compromiso Democrático de la Juventud Argentina" basado en la "Carta Democrática" firmada un año antes por los candidatos presidenciales de algunos partidos políticos previamente a los comicios electorales (La Nación, 29/10/1983, p. 9). ${ }^{9}$ Los jóvenes manifestaron la decisión de "resistir cualquier intento de golpe de Estado" pero en vez de limitarse solo a la dirigencia política, desplegaron una fuerte militancia territorial a través de puestos en distintos puntos de la ciudad en los cuales se invitó a la ciudadanía a firmar el compromiso democrático (Clarín, 2/11/1984, p. 19).

Si bien la defensa de la democracia fue el eje central y articulador que congregó a las juventudes políticas, en el plano económico las disidencias fueron más visibles. Estas comenzaron a expresarse a mediados del año 1984 con motivo de la convocatoria a una movilización contra el Fondo Monetario Internacional (FMI) y las presiones extranjeras. Los sentidos que los diferentes sectores juveniles le adjudicaron a la marcha provocaron cierto distanciamiento en la movilización. La Juventud Radical convocó a la misma como una adhesión al gobierno, lo cual generó fricciones con los demás agrupamientos que señalaron que la "unidad no significa[ba] uniformidad". Si bien se elaboró un acta de coincidencias, las juventudes políticas se movilizaron bajo diferentes consignas: la Juventud Radical lo hizo "contra la usura"; la Juventud Peronista llamaba a la "liberación" mientras que los sectores más radicalizados como la Juventud Intransigente y la Juventud Comunista se negaron a firmar el acta de coincidencias al ser la consigna del Partido Intransigente "primero los obreros, que esperen los banqueros" y la de los comunistas alusiva a la gestación de "una revolución” (Clarín, 23/6/1984, p. 10).

Las tensiones y las diferencias se agudizaron a lo largo del año 1985. Además de las movilizaciones por la defensa de la democracia, las consignas contra los organismos multilaterales de crédito fueron una de las preocupaciones principales que tensionaron los vínculos entre los agrupamientos juveniles. Mientras los radicales trataban de aquietar su participación en el MOJUPO en tanto buscaban evitar conflictos con su propia organización partidaria, las restantes orientaciones consideraban oportuno profundizar el estado de movilización y canalizar el descontento de los sectores de la sociedad que debían soportar el ajuste en términos económicos. De allí que algunos jóvenes, como los intransigentes, impulsaran la "nacionalización de la banca y el comercio exterior". En consecuencia, nuevamente la cuestión económica tuvo efectos regresivos en el movimiento que se agravaron con el transcurso del tiempo. 
La expresión del MOJUPO -como manifestación del movimiento nacional- irrumpió en la escena política marplatense a mediados del año 1983. Al igual que sus pares de la Capital Federal, entre sus objetivos primordiales se encontraban la salvaguarda y consolidación de la democracia como así también la defensa de los derechos humanos, combinados con una prédica fuertemente antiimperialista que atravesó sus posicionamientos políticos frente a la coyuntura nacional e internacional. Sin embargo, una diferencia central fue la ampliación de las fuerzas políticas que participaron dado que se caracterizó por la presencia de expresiones juveniles de partidos de izquierda como el Partido Obrero, el Movimiento al Socialismo y el Movimiento Demócrata Popular. También participaron activamente los jóvenes desarrollistas nucleados en el Movimiento de Integración y Desarrollo (MID), orientado a nivel nacional por Arturo Frondizi y Rogelio Frigerio. Pese a que en la Capital Federal ese grupo fue expulsado por su vinculación con sectores golpistas (Larrondo y Cozachcow, 2017, p. 58), en la ciudad Mar del Plata su participación fue inmutable. Como correlato de la adhesión que este partido logró en los comicios locales, ubicándose como tercera fuerza política luego del radicalismo y el peronismo, el desarrollismo reunió una gran cantidad de jóvenes bajo su órbita.

Entre los partidos mayoritarios la presencia del radicalismo fue imponente a partir de nutrir sus filas de jóvenes provenientes del ámbito universitario que iniciaban su militancia política en la recientemente fundada Franja Morada de la universidad local. Sumado al ascenso de la figura de Alfonsín, su éxito entre las preferencias juveniles fue predominante. Por el contrario, el peronismo se caracterizó por una constante desarticulación que se manifestó en el ámbito universitario - donde nunca se constituyó como una alternativa - y en el partidario a través de las múltiples expresiones existentes, entre las que predominaban a nivel local- las orientaciones más verticalistas a la figura de Isabel Martínez de Perón. Aún así contó con representantes dentro del MOJUPO, aunque sin una gravitación determinante. ${ }^{10}$

Además de los jóvenes radicales, quienes ostentaron mayor importancia en la coyuntura política marplatense fueron las juventudes nucleadas en el Partido Socialista Popular (PSP) y el Partido Intransigente (PI). Con una importante trayectoria política en la ciudad balnearia, el socialismo constituyó una de las alternativas más atractivas para los jóvenes, que se enrolaron particularmente en su línea más progresista orientada a nivel nacional por Guillermo Estévez Boero. Particularmente, su importancia radicó en la trayectoria de ese sector en el ámbito universitario, que fue el único que conservó su esquema desde los años setenta y sumó nuevos militantes durante los años ochenta. En el caso de la juventud del PI, su ascenso fue de la mano de la performance electoral del partido que se ubicó como lejana tercera fuerza. Los intransigentes conformaron un grupo sólido y una alternativa política al menos hasta 1987, cuando el partido sufrió un revés electoral y fue desplazado del tercer lugar por la Unión de Centro Democrático (UCeDé). Por entonces, sufrió un fuerte drenaje de sus militantes que, en su mayoría, continuaron su militancia en el Movimiento Todos por la Patria (MTP), y quienes permanecieron en el partido organizaron el Movimiento Intransigente Revolucionario (MIR) sin fuerte gravitación (Ferrari, 2019).

Con esos nucleamientos como protagonistas, la primera aparición de las juventudes políticas se produjo previo al acto electoral de octubre de 1983. En un documento que circuló en la prensa local afirmaban que:

Las Juventudes Políticas de Mar del Plata quieren hacer público que los jóvenes que fueron torturados, discriminados y perseguidos, los que hemos protagonizado en primera línea la batalla electoral, los que nos hemos peleado por los paredones y las pintadas, independientemente de nuestras diferencias políticas e ideológicas, rescatamos el mismo significado para nuestro voto y nuestra participación: la convicción de la necesidad de la democracia, y el objetivo común de forjar la unidad nacional, para asegurar la liberación nacional y social de nuestro pueblo (La Capital, Mar del Plata, 29/10/83, p. 7).

En este fragmento podemos observar la presencia de referentes simbólicos diversos -tales como liberación nacional-que reflejan la coexistencia de dos generaciones políticas (Vommaro y Blanco, 2017), la propia de los años setenta -quienes fueron torturados y perseguidos- y aquella que surgió durante la apertura política que condenó y tomó distancia de la lucha armada. No obstante esta diferenciación y como se enuncia en el documento, la defensa de la democracia actuó como causa aglutinante y movilizadora de las juventudes independientemente de las trayectorias políticas previas. 
Junto a estos pronunciamientos, en el plano cultural la realización de expresiones artísticas y musicales fueron espacios privilegiados para canalizar los reclamos compartidos vinculados a las violaciones de los derechos humanos. Coordinado en conjunto con la filial local de Madres de Plaza de Mayo, el "Festival Folklórico Popular Canto a la Libertad y la Esperanza"-realizado durante los meses de enero desde 1984- fue una de las actividades más convocantes a la cual se abocaron las juventudes políticas de la ciudad que contaron con la participación de reconocidos artistas locales y nacionales como León Gieco y Víctor Heredia (Alberto Rodríguez, comunicación personal, 6 de diciembre de 2016). Al ser Mar del Plata la ciudad balnearia de veraneo por excelencia en la Argentina, la realización de este evento se justificaba por la masiva concurrencia de veraneantes que arribaban desde distintos puntos del país. De esa forma, ese espacio se convirtió en una de las principales estrategias de visibilización donde manifestar el reclamo por las violaciones a los derechos humanos.

Las coincidencias también se expresaron en el análisis de algunos aspectos de la coyuntura nacional e internacional que derivaron en posiciones políticas comunes, las cuales fueron plasmadas en diversos documentos. Particularmente, en el ámbito nacional suscitó especial interés el conflicto por el canal de Beagle respecto del cual se pronunciaron por una "solución pacífica y negociada" y convocaron a marchar por "La Paz y la Democracia” (La Capital, Mar del Plata, 14/6/83, p. 2.; Clarín, 3/7/1983, p. 6 y 7 . y 20/11/1984, p.11). ${ }^{11}$ También la conmemoración de los aniversarios de la Guerra de Malvinas concitó gran atención. Al respecto, con motivo del primero en un comunicado señalaban que:

Nos hacemos presentes para concretar nuestro homenaje a los compatriotas y especialmente a los jóvenes argentinos que
cayeron en defensa de la irrenunciable soberanía territorial, enfrentando la acción conjunta del colonialismo inglés y el
imperialismo norteamericano, conjugados en la OTAN. No olvidamos que allá lejos, desde hace un año, yacen jóvenes
argentinos, y que mercenarios concretaron el crimen y atropello sobre un pedazo de tierra latinoamericana. No olvidamos
también que estrategia, diplomacia y economía estadounidenses se sumaron para enfrentar a los argentinos. No olvidamos
que el pueblo, el que sufre las consecuencias del drama nacional, pleno de patriotismo, fue solidario con sus hijos en la
lucha de Malvinas. No olvidamos la vasta solidaridad latinoamericana en torno a este conflicto que las naciones hermanas
hicieron suyo (...) No olvidamos que todavía falta liberar nuestras Malvinas, nuestra Patria y el conjunto de las naciones
latinoamericanas del dominio del capital extranjero y de las asechanzas de las superpotencias y que la unidad que hoy
expresamos está al inicio del camino liberador. Será el pueblo argentino, expresado en democracia, en un estado de derecho
y con las instituciones republicanas funcionando, quien tomará sobre su espalda el compromiso de asegurar definitivamente
la soberanía nacional (La Capital, Mar del Plata, $14 / 6 / 83$, p. 8).

Este documento permite visualizar -como se mencionó anteriormente- el peso simbólico que adquirió la Guerra de Malvinas a partir de una idea de "generación” afectada por ella; a la vez, aparece la resignificación de las formas de lucha. Lejos de renunciar a la "causa" Malvinas, el fragmento reivindica el reclamo por la soberanía territorial y concibe a la democracia -a través de sus instituciones-como medio legítimo para alcanzar la definitiva soberanía nacional sobre las islas. No obstante, puede observarse cómo el reclamo excede los límites nacionales destacándose la solidaridad de los países latinoamericanos y los efectos del imperialismo norteamericano, aspecto que evidencia cierta continuidad respecto de la década previa, en la cual primó la concepción de unidad regional latinoamericana como un valor y un objetivo a defender y la existencia de una dependencia imperial expresada en este conflicto a través de Inglaterra-adversario principal en el conflictoy Estados Unidos como partícipe secundario.

En sintonía con la prédica antiimperialista y con la movilización realizada el 22 de junio de 1984 en Capital Federal, el MOJUPO marplatense realizó la "Marcha contra la dependencia, el imperialismo, la oligarquía y la patria financiera", que contó no solo con las adhesiones de las ramas juveniles de los partidos políticos que participaban del MOJUPO, sino también de los Centros de Estudiantes nucleados en la Federación Universitaria Marplatense (FUM), Madres de Detenidos-Desaparecidos, el Sindicato Obrero de la Industria del Pescado (SOIP) y la Confederación General del Trabajo (CGT) Regional Mar del Plata. Algunas de las consignas que se expusieron en la marcha fueron "Patria si, colonia no", "Alerta que camina el antiimperialismo por América Latina” y "Con el hambre del pueblo no vamos a pagar" (Clarín, 
23/6/1984, p. 10; La Capital, Mar del Plata, 23/6/84, p. 14). En el mismo sentido, en el mes de noviembre de 1984 se convocó a una nueva marcha bajo el lema "No al FMI". Estas movilizaciones y las consignas que las motivaron estuvieron vinculadas a la coyuntura económica que atravesó el país hacia el final de la gestión de Bernardo Grispun producto de la creciente inflación y la cuantiosa deuda externa heredada de la dictadura, cuya negociación con los organismos internacionales de crédito supuso la adopción de políticas económicas ortodoxas que derivaron en la consolidación de un nuevo poder económico surgido de la etapa previa (Basualdo, 2010, p. 227).

En síntesis, el MOJUPO articuló y estableció las posiciones políticas sobre las temáticas que inquietaban por igual a los jóvenes militantes provenientes de distintas trayectorias, entre las cuales se destacaban como grandes ejes la democracia, el antiimperialismo, la unidad nacional, la soberanía y la defensa de los derechos humanos. Al igual que en Capital Federal, su origen puede ubicarse hacia mediados de 1983 cuando se hace público su posicionamiento sobre la defensa de la democracia ante el inminente acto electoral.

Para el caso de Mar del Plata, podemos advertir que la periodización esbozada por Larrondo y Cozachcow coincide en la primera etapa dado que se trató de una experiencia efímera cuya participación en las movilizaciones tuvo vigencia sólo hasta fines del año 1984. A partir del año siguiente, fue diluyéndose progresivamente al disminuir sus actividades, tal como señalan algunos de sus integrantes, aspecto que se reflejó en la prensa local que durante su existencia difundió sus escritos y movilizaciones. El último comunicado que emitió el MOJUPO marplatense fue en marzo de 1985 con motivo de un nuevo aniversario del golpe de Estado de 1976. El documento, además de defender la institucionalidad del país, reforzaba las críticas imputadas en el ámbito económico al señalar que:

Los enemigos del país miran cómo vamos malgastando el tiempo de la soberanía popular sin poner la economía en manos argentinas, y sin erradicarse definitivamente la patria financiera, la especulación, el mercado negro, sin dar real participación a las mayorías nacionales en la economía del país (La Capital, Mar del Plata, 23/3/85, p. 5).

Menos problemático que sus pares de la Capital Federal, el fragmento muestra que el rumbo económico fue una de las preocupaciones centrales de los jóvenes marplatenses que expresaron su disconformidad respecto de ese ámbito. Lejos de sostener un diagnostico complaciente hacia la gestión radical, el conjunto de las juventudes políticas adjudicaron valoraciones negativas, incluyéndose a la Juventud Radical. En buena medida ello fue resultado de una juventud peronista desarticulada y atónita en la ciudad, en contraposición a los jóvenes radicales que exhibieron una faceta más crítica y de relativa autonomía respecto de las autoridades partidarias locales - referenciadas en el balbinismo- y sin demasiada organicidad en términos de líneas partidarias. ${ }^{12}$ Sin embargo, al diagnóstico económico adverso se sumó, un año más tarde, la sanción de las leyes de Punto Final y Obediencia Debida que minaron las bases de coincidencia e incidieron en la descomposición del MOJUPO. La Juventud Radical que había constituido una de las agrupaciones más dinámicas del espacio, en tanto oficialismo sufrió un fuerte desgaste, pérdida de credibilidad y militantes. En palabras de uno de ellos:

\footnotetext{
Nosotros no estábamos de acuerdo con ninguna de las dos leyes. Obviamente lo veíamos (...) no te voy a decir como una traición porque no sería así, pensábamos que ninguno de nuestros referentes políticos nos podía traicionar. Lo que si veíamos, por lo menos yo y algunos más, era un acto de debilidad política. Era como que nuestro propio gobierno había atacado muchos frentes y después retrocedía, encarábamos la reforma gremial y enfrentábamos a los sindicatos y de repente retrocedíamos, la lucha contra el poder militar, sensible... y después retrocedíamos con la Obediencia Debida y Punto Final. Veíamos que el proceso marcaba debilidades políticas... El sector concentrado de la economía, sacábamos el Plan Austral con participación del Estado, un control y retrocedíamos y después venía al final el Plan Primavera y la privatización de Austral... y empezamos ahí con las privatizaciones. Encima Sourouille que venía de la Soborne y de una formación de centroizquierda se derechizaba. Nosotros estábamos seguros que no eran cambios ideológicos porque nadie puede virar así en la geometría política con tanta velocidad, pero sí porque te doblan las manos. No entendíamos que teníamos un debate entre los que traicionaron o no sino que en ese debate lo que sentíamos [era] la necesidad de tenerlo para que no se sintieran solos nuestros referentes y poder apoyarlos (Fernando Coppari, comunicación personal, 13 de octubre de 2016).
} 
Frente a la acuciante situación que atravesaba el gobierno de Alfonsín en todos los frentes su participación en tanto oficialismo comenzó a ser cuestionada, y la apuesta de ese sector por la construcción política dentro del MOJUPO fue perdiendo terreno para centrarse en el debate interno que tales medidas generaron en el interior de su espacio de militancia. A la vez, ante el desencanto y la percepción de injusticia, la militancia partidaria tuvo diferentes derivas, en algunas agrupaciones hubo fracturas optándose -como el caso del PIpor nucleamientos más radicalizados como el MTP, alejamientos o bien realineamientos. De esta manera, la experiencia del MOJUPO fue progresivamente diluyéndose.

\section{A MODO DE SÍNTESIS}

En este trabajo nos hemos centrado en analizar la participación de los jóvenes durante la apertura democrática a través de la experiencia del MOJUPO. Vimos cómo se configuró como el espacio en el cual las juventudes de los partidos políticos se abocaron a la construcción de causas colectivas que tuvieron como eje transversal la reivindicación y consolidación de la democracia, la defensa de los derechos humanos y un fuerte posicionamiento político antiimperialista que moduló sus alocuciones en temáticas de índole nacional e internacional. Como han señalado Vommaro y Cozachcow (2015) durante la apertura democrática las juventudes de los años setenta aparecen en el ideal regulatorio que marcan las experiencias de las juventudes de los años ochenta. La coexistencia de estas dos generaciones políticas está dada por el hecho de que los referentes simbólicos y las reivindicaciones esgrimidas en el periodo previo no perdieron vigencia en la nueva coyuntura política, sino que se modificaron los medios para alcanzar tales fines. Así, se produjo una revalorización de la democracia, la cual emergió como causa que aglutinó al conjunto de las juventudes políticas en su reivindicación y defensa y se transformó en eje central de sus movilizaciones.

Para finalizar, cabe afirmar que, si bien existió en el plano discursivo una ruptura evidente respecto de las juventudes del periodo previo, en particular en el alejamiento por el empleo de los métodos violentos, dicha ruptura no se tradujo en un abandono total de las prácticas políticas llevadas a cabo en los años setenta. Muestra de ello fue el empleo de la movilización permanente bajo las consignas que congregaron a los jóvenes una década atrás. Es decir que, si bien se introducen especificidades propias de la coyuntura política y se aboga por una mayor institucionalidad, existe cierta continuidad con las prácticas políticas preexistentes. En buena medida, en este periodo la ruptura estuvo dada por el sentido que esas reivindicaciones adquirieron en la nueva coyuntura democrática.

\section{BiBLIOgRAFíA}

Aboy Carlés, G. (2001). Las dos fronteras de la democracia argentina: la reformulación de las identidades politicas de Alfonsin a Menem. Buenos Aires: Homo Sapiens.

Basualdo, E. (2010). Estudios de historia económica argentina. Buenos Aires: Siglo XXI.

Cristal, Y. (2017). El movimiento estudiantil de la Universidad de Buenos Aires en el final de la última dictadura (1982-83). Sociohistórica, 40.

¿Feld, C. y Franco, M. (comps.) (2015). Democracia hora cero. Actores, políticas y debates en los inicios de la posdictadura. Buenos Aires: Fondo de Cultura Económica.

Ferrari, M. (2019). La Juventud Intransigente en un juego de escalas. Experiencias y derivas de la militancia marplatense en democracia. XVII Jornadas Interescuelas de Historial Departamento de Historia. Catamarca: Universidad Nacional de Catamarca.

Ferrari, M. y Closa, G. (2015), Los partidos políticos mayoritarios durante la reconstrucción democrática. Córdoba y Buenos Aires, 1982-1991. En M. Ferrari y M. Gordillo (comps.), La reconstrucción democrática en clave provincial. (pp. 29-64). Rosario: Prohistoria Ediciones. 
Guber, R. (2001). ¿Por qué Malvinas? De la causa nacional a la guerra absurda. Buenos Aires: Fondo de Cultura Económica.

Larrondo, M. y Cozachcow, A. (2017). Un llamado a la unidad. La experiencia del Movimiento de Juventudes Políticas (MOJUPO) en la transición a la democracia. En M. Vázquez, P. Vommaro, P. Nuñez y R. Blanco (comps.), Militancias juveniles en la Argentina democrática. Trayectorias, espacios y figuras del activismo (pp. 51-72). Buenos Aires: Imago Mundi.

Leuco, A. y Díaz, J. A. (1987). Los herederos de Alfonsin. Buenos Aires: Sudamericana-Planeta.

Lorenz, F. (2006). Las guerras por Malvinas. Buenos Aires: Edhasa.

Palermo, V. (1987). Movimientos sociales y partidos políticos: aspectos de la cuestión en la democracia emergente en la Argentina. En E. Jelin (comp.), Movimientos sociales y democracia emergente. Buenos Aires: Centro Editor de América Latina.

Planas, E. (2011). Las Juventudes Politicas de Córdoba. Luchamos por una causa. Córdoba: Espartaco.

Pozzoni, M. (2017). Leales. De la Tendencia Revolucionaria a la Juventud Peronista Lealtad. Buenos Aires: Imago Mundi.

Pozzoni, M. (2011). Los coordinadores bonaerenses: una mirada desde la revista Generación '83. En M. Fabris y R. Tortorela (comps.), Democracia en reconstrucción: mosaico histórico de los años ochenta (pp. 51-90). Mar del Plata: EUDEM.

Quiroga, H. (1996). Esfera pública, política y ciudadanía: dilemas de la política democrática argentina. Revista internacional de filosofía politica, 7, 141-158.

Quirós, J. (2014). Militante. En A. Adelstein y G. Vommaro (coords.), Diccionario del léxico corriente de la politica argentina. Palabras en democracia (1983-2013) (pp. 251-254). Los Polvorines: UNGS.

Vommaro, P. y Blanco, R. (2017). Otros caminos, otros destinos. Transformaciones en los espacios y prácticas cotidianas de participación juvenil en los años ochenta. En M. Vázquez, P. Vommaro, P. Nuñez y R. Blanco (comps.), Militanciasjuveniles en la Argentina democrática. Trayectorias, espaciosy figuras del activismo (pp. 1-25). Buenos Aires: Imago Mundi.

Vommaro, P. y Cozachcow, A. (2015). Militancias juveniles en los 80: acercamientos a las formas de participación juveniles en la transición democrática. XV Jornadas Interescuelas de Historial Departamento de Historia. Comodoro Rivadavia: Universidad Nacional de la Patagonia San Juan Bosco.

\section{Notas}

1 Por cultura politica se entiende al "conjunto de valores, ideas, sentimientos y prácticas de los que participa un conjunto social, o grupos y sectores dentro de la sociedad, que afectados emotiva o racionalmente por lo político, se movilizan para expresar su adhesión o rechazo a determinado estado de cosas" (Citado en Pozzoni, 2017, p. 19)

2 La Guerra de Malvinas se desencadenó el 2 de abril de 1982, cuando las tropas argentinas desembarcaron en las islas. Al reflotar una causa de unión nacional (Guber, 2001), el objetivo implícito de este proyecto consistió en relegitimar el régimen militar que era asediado por las demandas de una sociedad postergada en sus derechos. La población civil -que dos días antes había sido reprimida en la movilización convocada por la CGT a Plaza de Mayo- apoyó decididamente la "causa Malvinas". Tras la capitulación argentina el 14 de junio de 1982, se produjo la crisis del gobierno militar, el presidente de facto Leopoldo F. Galtieri renunció y fue reemplazado por Reynaldo Bignone -proveniente del Ejército-, mientras que la Armada y la Fuerza Aérea abandonaron la Junta Militar (Lorenz, 2006).

3 Lorenz señala que el grueso de las tropas destinadas a Malvinas estaba nutrido por más de doce mil quinientos jóvenes conscriptos de entre 18 y 20 años de edad, en general pertenecientes a las clases 1962 y 1963 (Lorenz, 2006).

4 Para un análisis de la revista Generación' 83 ver Pozzoni, 2011.

5 La Multipartidaria fue una coalición política conformada con el fin de presionar a la dictadura en un momento de crisis interna ocasionada por la situación económica y la resistencia civil en aumento. La integraban el Partido Justicialista, la Unión Cívica Radical, el Movimiento de Integración y Desarrollo (MID), el Partido Intransigente (PI) y la Democracia Cristiana (DC).

6 Participaban de las Juventudes Políticas Argentinas las regionales de la Juventud Peronista, grupos ligados al Partido Revolucionario de los Trabajadores (PRT), comunistas, socialistas, demócratas cristianos e intransigentes (Planas, 2011, 
p. 19). La Juventud Radical se retiro de esa instancia cuando la organización Montoneros pasó a conducir el espacio (Leuco y Díaz, 1987, p. 272).

7 Estuvo conformada por militantes de hasta 35 años de las juventudes de los partidos justicialista, UCR, MID, DC, PI, PC, PSP, Partido Socialista Auténtico, Socialista Unificado, Confederación Socialista Argentina y Conservador Popular.

8 La CONADEP estuvo integrada por individuos de la sociedad civil y fue la encargada de reunir y sistematizar las denuncias sobre las desapariciones y la sustracción de niños, cuyo objetivo final sería la confección de un informe con la información reunida. Entre sus miembros más destacados se encontraron Ernesto Sábato, Magdalena Ruíz Guiñazú, Hilario Fernández Long y Gregorio Klimobsky, entre otros.

9 La "Carta Democrática" fue impulsada por la DC. Constaba de doce puntos por los cuales los dirigentes de los partidos políticos se comprometían a garantizar la estabilidad institucional del futuro gobierno y actuar en conjunto frente a cualquier amenaza de interrupción democrática. Fue suscripta por los candidatos presidenciales, entre ellos por la DC, Francisco Cerro; por el justicialismo, Ítalo Luder; por la UCR, Raúl Alfonsín; y por el MID, Rogelio Frigerio.

10 Ferrari y Closa señalan que -a falta de corrientes definidas- los contemporáneos peronistas identificaban cuatro grandes constelaciones: el antiverticalismo, que se oponía a la conducción de la viuda de Perón como jefa del movimiento, defendían la jerarquización del partido por sobre el movimiento y la democracia interna; el verticalismo, conformado por diversos grupos que compartían la subordinación a la jefatura de Isabel Perón; la izquierda, de escaso raigambre en el partido por lo cual se veía obligada a negociar; y el centro, que incluía a un amplio espectro que rescataba la condición movimentista del peronismo, tenían una larga trayectoria en él y algunos de ellos se nuclearon en el Movimiento de Unidad, Solidaridad y Organización (MUSO) que se propuso como una alternativa democratizadora del peronismo (Ferrari y Closa, 2015, p. 32).

En la ciudad de Mar del Plata existieron expresiones de todas estas constelaciones con mayor predominio de los sectores verticalistas. Por los antiverticalistas se expresó la Coordinadora Juventud Justicialista que respondía a Ángel Federico Robledo; por los verticalistas las agrupaciones Generación Intermedia del MNJ MdP, Convergencia Justicialista, JP Coordinadora Cuarta Rama, Agrupación Verticalista, Agrupación Vecinalista por Isabel Perón, Agrupación Acción y Recuperación” y; por el centro, la expresión marplatense del MUSO.

11 Los conflictos limítrofes con Chile son de larga data. Sin embargo, cobraron fuerte resonancia en febrero de 1978 cuando el gobierno militar de Videla rechazó el laudo papal con motivo del arbitraje por la soberanía de la zona del Canal de Beagle. Esta decisión creó un clima bélico en el país, que estuvo a punto de iniciar una guerra con Chile. En 1980 se presentó una nueva propuesta desde el Vaticano que fue letargada y quedó en suspenso luego de la Guerra de Malvinas. El gobierno de Raúl Alfonsín heredó el conflicto irresuelto y para ello convocó a un pleisbicito para aceptar o no los resultados de la mediación papal. Luego de imponerse en el pleisbicito la aceptación de la propuesta papal, se retomaron las negociaciones con Chile por la vía diplomática y se logró superar el diferendo austral mediante la firma del Tratado de Paz y Amistad de 1984.

12 La juventud radical se nutrió de los grupos de militantes identificados con el alfonsinismo que se formaron en las diferentes facultades de la Universidad Nacional de Mar del Plata. Una vez articulados y conformada la agrupación Franja Morada se incorporaron a las filas del partido. Recién en 1985 se identificaron dentro de la Junta Coordinadora Nacional liderada por el Diputado Nacional Federico Storani. 